\title{
Article \\ Development of a Vibration Technique Based on Geometric Optimization for Fatigue Life Evaluation of Sandwich Composite Structures
}

\author{
Marco Menegozzo ${ }^{1, *(1)}$, Frederick A. Just-Agosto ${ }^{1}{ }^{\mathbb{D}}$, David Serrano Acevedo ${ }^{1}$, Basir Shafiq ${ }^{2}$, Andrés Cecchini ${ }^{1}$, \\ Joaquín M. Valencia Bravo ${ }^{3}$ (D) and Uday K. Vaidya ${ }^{4,5,6}$ \\ 1 Department of Mechanical Engineering, University of Puerto Rico at Mayagüez, Mayagüez, PR 00681, USA; \\ frederick.just@upr.edu (F.A.J.-A.); david.serrano@upr.edu (D.S.A.); andres.cecchini@upr.edu (A.C.) \\ 2 Department of Engineering Sciences and Materials, University of Puerto Rico at Mayagüez, \\ Mayagüez, PR 00681, USA; basir.shafiq@upr.edu \\ 3 Orlando Campus, Polytechnic University of Puerto Rico, Orlando, FL 32825, USA; jvalencia@pupr.edu \\ 4 Tickle College of Engineering, University of Tennessee, Knoxville, TN 37996, USA; uvaidya@utk.edu \\ 5 Institute for Advanced Composites Manufacturing Innovation (IACMI), Knoxville, TN 37932, USA \\ 6 Manufacturing Sciences Division, Oak Ridge National Laboratory, Oak Ridge, TN 37830, USA \\ * Correspondence: marco.menegozzo@upr.edu; Tel.: +1-787-832-4040
}

check for updates

Citation: Menegozzo, M.; Just-Agosto, F.A.; Serrano Acevedo, D.; Shafiq, B.; Cecchini, A.; Valencia Bravo, J.M.; Vaidya, U.K

Development of a Vibration Technique Based on Geometric Optimization for Fatigue Life Evaluation of Sandwich Composite Structures. Appl. Sci. 2022, 12, 16. https://doi.org/10.3390/ app12010016

Academic Editors: Elza Maria Morais Fonseca and Hernâni Miguel Reis Lopes

Received: 16 November 2021 Accepted: 16 December 2021 Published: 21 December 2021

Publisher's Note: MDPI stays neutral with regard to jurisdictional claims in published maps and institutional affiliations.

Copyright: (C) 2021 by the authors. Licensee MDPI, Basel, Switzerland. This article is an open access article distributed under the terms and conditions of the Creative Commons Attribution (CC BY) license (https:// creativecommons.org/licenses/by/ $4.0 /)$.

\begin{abstract}
A major obstacle to obtaining cost-effective experimental data on the fatigue life of sandwich panels is the prohibitive amount of time and cost required to carry out millions of cycles. On the other hand, vibration techniques applied to sandwich geometries fail to match the stress patterns that are obtained from standard flexural fatigue tests. To overcome such limitations, a vibration-based fatigue technique is proposed, which entails the use of sandwich specimens whose geometries are optimized to reproduce the stress distribution observed during three point bend loading while vibrating at the first resonant frequency. The proposed vibration technique was experimentally validated. The results, compared with the average number of cycles to failure at different stress ratios obtained via the Three-Point Bending test, showed high levels of accuracy. The proposed method is robust and time effective and indicates the possibility of attaining fatigue lifetime prediction of a wide class of composite elements, such as sandwich panels.
\end{abstract}

Keywords: fatigue; vibration; sandwich panels; natural frequencies; three-point bending; optimization

\section{Introduction}

The high strength-to-weight ratio offered by sandwich composites has significantly increased their use in transportation, military applications such as bridge decks and industrial applications. In order that these structures resist the various loads encountered during their lifetime (from static to repeated random loading), fatigue lifetime assessment is critical in their design. Figure 1 shows the schematic of a typical sandwich composite consisting of a core and bonded face sheets.

Literature on sandwich composites has focused on damage accumulation mechanisms, the effect of notches, environmental effects and the effect of frequency at various stress levels [1-14]. Fatigue life characterization is performed within the limitations imposed by the equipment used [15-18]. Most of the specimen testing occurs in expensive tension compression machines that operate at low frequencies $(0-10 \mathrm{~Hz})$. Disagreement in experimental results has been seen in the literature $[2,3]$, since material testing systems and their conditions inconsistently vary from one laboratory to another. Fatigue analysis of composite materials may require probabilistic methods $[1,2,7,8]$ due to the random data scatter that is typically found in experiments. In order to obtain reliable results, repeated experimentation is required [15]. Depending upon the material being tested, this can lead to excessive cost even before the actual design process has begun. Furthermore, the test machines can, at times, create inertia frequency effects and temperature changes [2,12,19-21]. 


\section{TOP FACE SKIN}

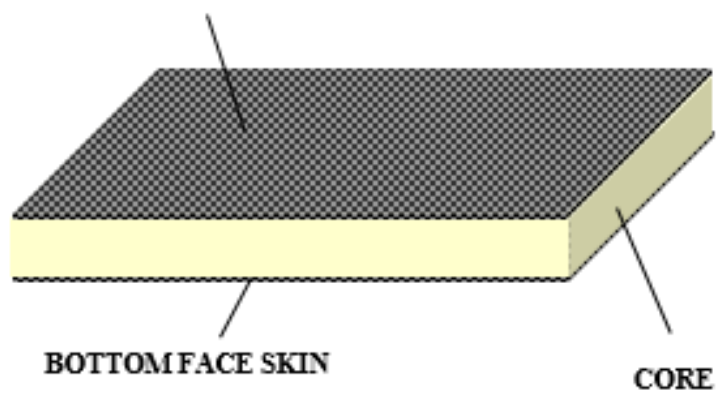

Figure 1. Schematic of a sandwich composite.

Typical vibration testing is a damage evaluation technique that uses frequency changes and modal property variations [22,23]. This method can also be implemented to assess fatigue lifetime [24-32]. However, the stress patterns produced in beam vibration testing do not generally match those generated in standard three-point bending test procedures, as described in [33]. Therefore the patterns produced in vibration testing are not consistent with standard test results of flexural fatigue lifetime tests.

This research proposes a novel vibration technique that can be used to determine the fatigue life of a sandwich composite. Instead of vibrating a standard prescribed shape, such as a rectangular beam, a geometric optimization of the test specimen is performed that creates a desired stress pattern emulating three-point bending flexural fatigue testing [33]. The hypothesis behind this idea is that the stress pattern produced by vibration fatigue testing should yield results matching conventional fatigue testing, as long as the frequency effects do not affect the material properties significantly. The main difference between this approach and work performed previously [34-36] is that, for the first time, this technique is actually verified against low frequency three-point bending tests and is applied to a sandwich core composite as opposed to homogeneous metals. Additionally, this procedure uses flexural vibration modes whereas other references [34-36] use torsional modes of vibration.

Traditional fatigue testing machines operate between $1 \mathrm{~Hz}$ and $15 \mathrm{~Hz}$; however, inertial jig effects usually limit testing frequencies below $5 \mathrm{~Hz}$ for most engineering materials. The literature provides contrasting opinions on whether an increase in frequency can lead to an improvement or a reduction in the fatigue life [19-21]. According to some authors $[11,12,19,37]$, temperature increase affects material properties and reduces fatigue life in sandwich composites. This is mostly produced by hysteretic heat generation that occurs between the different constitutive layers of the sandwich composite. In the case of foams in an environment with constant temperature, the temperature rise is typically prevented by the heat dissipation [1,2,37]. Vibration tests performed on a polyurethane foam showed a temperature increase of no more than $2{ }^{\circ} \mathrm{C}[37]$, an amount that is considered small enough not to affect the properties of such materials.

The proposed methodology was used to study the fatigue life characteristics of polyurethane foam sandwich composites, where carbon/epoxy face sheet constituents are significantly stiffer, and the effects of temperature increases in testing are negligible. The results show reasonably good correlation data to justify the use of this technique as a viable substitute for conventional low frequency $(1-5 \mathrm{~Hz})$ fatigue testing in practical applications.

\section{Materials and Methods}

\subsection{Analytical Framework}

The vibration specimen design process is iterative. To design the specimen, a model capable of predicting the variations in frequency and mode shapes due to geometric changes is required. Finite Element Analysis (FEA) was used during the modeling. The sandwich construction consisted of beams with 0-90 carbon fiber face sheets bonded with epoxy 
resin to a polyurethane foam core. Beams were constructed using Vacuum-Assisted Resin Transfer Molding (VARTM). The core was modeled as linear elastic isotropic and the face sheet was modeled as linear elastic transversely orthotropic. The cores were manufactured using polyurethane foam whose properties were available from the manufacturer [38]. The face sheet material properties were not available and were estimated by using a combination of FEA and experimental vibration testing [39].

\subsection{Establishing the Face Sheet Properties Values}

Face sheet material properties were determined by numerically varying their property values in the FEA of a rectangular cantilever beam until an adequate match with the first three natural frequencies from experimental vibration testing of the same beam was obtained. Six sandwich composite rectangular beams with a length of $40 \mathrm{~cm}$, a width of $3.81 \mathrm{~cm}$, and a core height of $1.27 \mathrm{~cm}$ were manufactured. Experimental vibration values were acquired by vibrating a double back-to-back cantilever beam configuration with random white noise. The averages of the first three natural frequencies were $27.5 \mathrm{~Hz}$, $245 \mathrm{~Hz}$, and $665 \mathrm{~Hz}$, respectively. Both the face sheet and core were modeled using solid brick elements. The interface between the face sheet and core was assumed to be perfectly bonded, which means that no delamination was allowed. A schematic of the FEA mesh is shown in Figure 2.

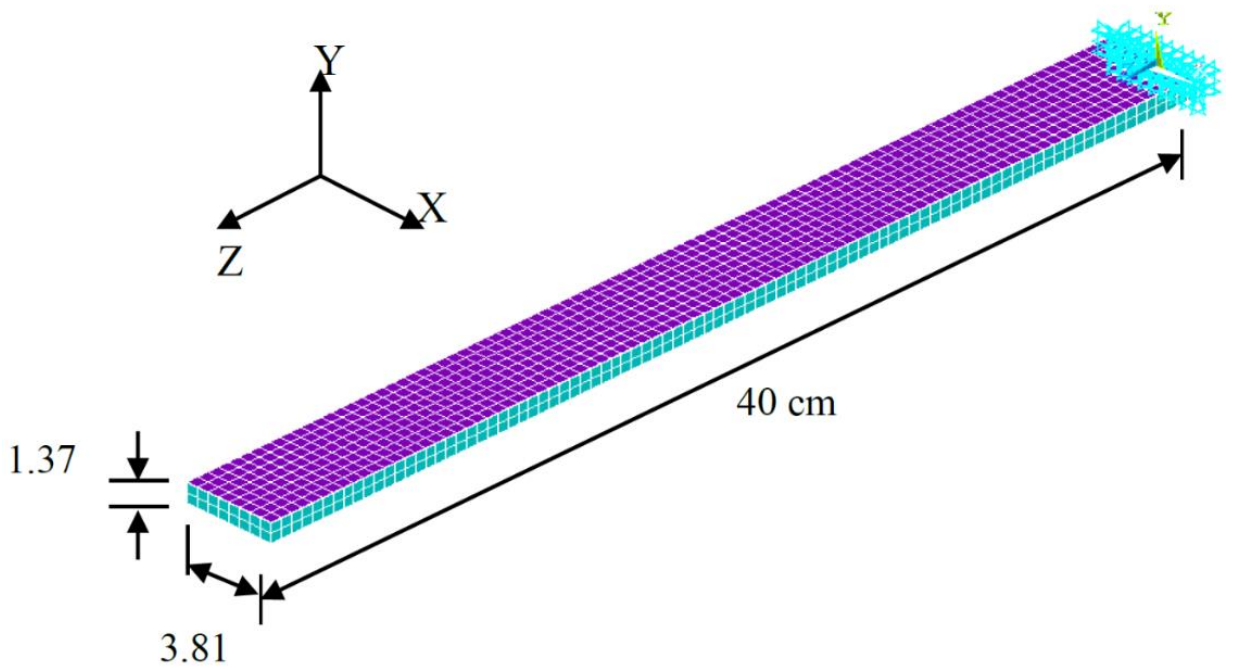

Figure 2. Finite Element mesh used in FEA for the rectangular sandwich cantilever beam.

The face sheet material properties needed in the FEA are the mass density $\rho$, the modulus of elasticity, $E_{x}, E_{y}, E_{z}$, the shear modulus of elasticity, $G_{x y}, G_{x z}, G_{y z}$, and the Poisson ratio, $v_{x y}, v_{x z}, v_{y z}$. The influence these material properties have in predicting the natural frequencies was examined. A sensitivity analysis was performed in which each individual face sheet material property value was significantly increased and decreased $( \pm 60 \%)$ while the other values were held constant [39]. Core material property values available from the manufacturer were not varied during this process. The results showed that the face sheet properties $E_{x}, E_{y}, G_{x z}, G_{y z}$, and $v_{x y}, v_{x z}, v_{y z}$ had little or no influence in predicting the natural frequencies. Thus, the need to accurately obtain ten variables for FEA was reduced to three $\left(\rho, E_{z}\right.$, and $\left.G_{x y}\right)$.

These three face sheet values were determined using a quadratic interpolation method [40]. Once all three face sheet property values were obtained, FEA vibration frequencies were calculated and the accuracy of the interpolations was examined with the following objective function:

$$
f\left(\omega_{1}^{n}, \omega_{2}^{n}, \omega_{3}^{n}\right)=\left(\frac{\omega_{1}^{e}-\omega_{1}^{n}}{\omega_{1}^{e}}\right)^{2}+\left(\frac{\omega_{2}^{e}-\omega_{2}^{n}}{\omega_{2}^{e}}\right)^{2}+\left(\frac{\omega_{3}^{e}-\omega_{3}^{n}}{\omega_{3}^{e}}\right)^{2}
$$


Here $\omega_{1}^{n}, \omega_{2}^{n}$ and $\omega_{3}^{n}$ are the first three natural frequencies predicted via FEA, and $\omega_{1}^{e}, \omega_{2}^{e}$ and $\omega_{3}^{e}$ are the first three natural frequencies measured through experimental testing. This procedure was repeated until the objective function value fell within a desired tolerance. The initial values of the density, $\rho$, the longitudinal modulus of elasticity, $E_{z}$, and the transverse modulus of elasticity, $G_{x y}$, were $1500 \mathrm{~kg} / \mathrm{m}^{3}, 8000 \mathrm{MPa}$, and $5500 \mathrm{MPa}$, respectively, yielding an initial objective function value of 0.02 . This process was terminated after six iterations, when the objective function yielded a value of $6.27 \times 10^{-4}$. The minimizing behavior of the objective function using this method is shown in Figure 3.

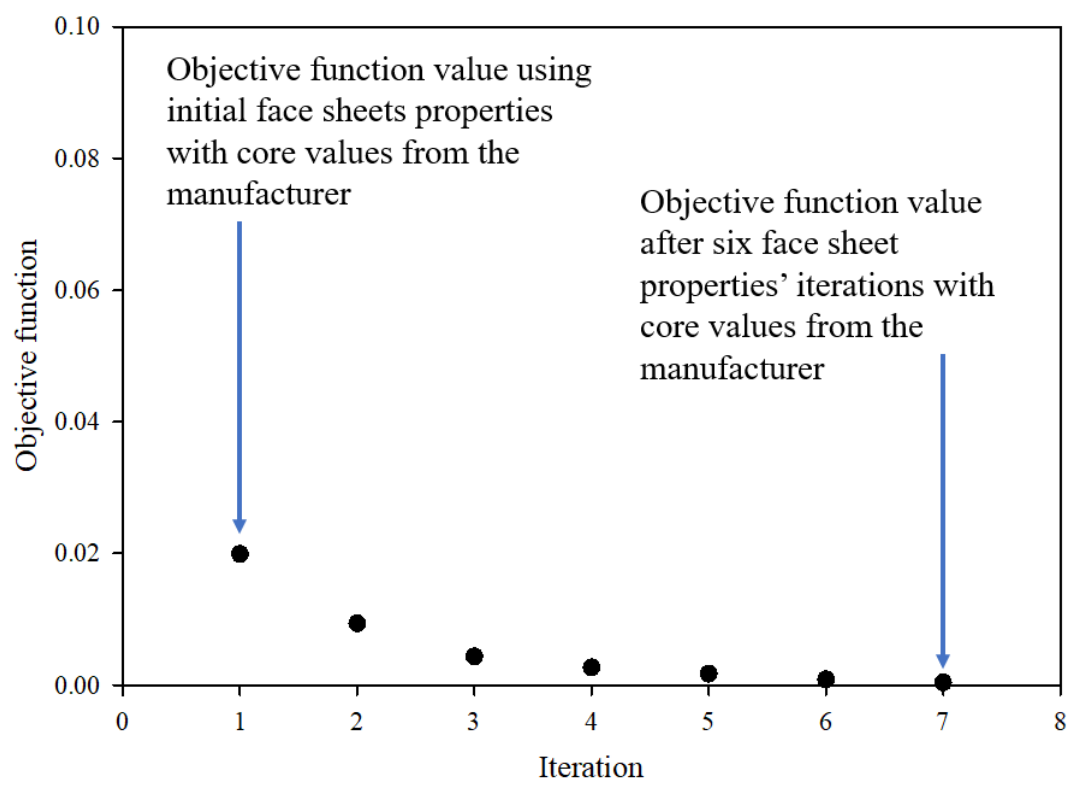

Figure 3. Objective function value as a function of properties iterations.

The determined properties of the face sheet allowed accurate prediction of the first three experimental natural frequencies, with the maximum error observed being $4 \%$. The determined material properties, along with the face sheet properties that did not influence the natural frequency calculations in FEA, are given in Table 1.

Table 1. Material property values used in FEA.

\begin{tabular}{ccc}
\hline Property & Face Sheet & Foam Core \\
\hline Density $\left(\mathrm{kg} / \mathrm{m}^{3}\right)$ & 1117 & 96 \\
\hline Longitudinal Modulus of Elasticity $E_{Z}(\mathrm{MPa})$ & $40 \times 10^{3}$ & 21.507 \\
\hline Transversal Modulus of Elasticity ${ }^{*} E_{x}, E_{y}(\mathrm{MPa})$ & $40 \times 10^{3}$ & 21.507 \\
\hline Longitudinal Shear Modulus of Elasticity $G_{X Y}(\mathrm{MPa})$ & $10 \times 10^{3}$ & 8.994 \\
\hline Transversal Shear Modulus of Elasticity $* G_{X Z}, G_{Y Z}(\mathrm{MPa})$ & $10 \times 10^{3}$ & 8.626 \\
\hline Poisson's Ratio ${ }^{*} v_{x y}, v_{x z}, v_{y z}$ & 0.35 & 0.3 \\
\hline
\end{tabular}

* Predicted FEA vibration natural frequencies are not sensitive to significant changes of these properties.

\subsection{Specimen Design}

The design of the vibration test specimen was an iterative process. The vibration specimen geometry was obtained by comparing the first resonance vibration stress pattern with the stress pattern of the beam undergoing three-point bending. The vibration specimen design flowchart is given in Figure 4.

The stress ratio corresponding to the top face sheet centerline profile of a sandwich beam undergoing three-point bending is shown in Figure 5. Here, the stress ratio is defined 
by $R=\left(\sigma / \sigma_{u l t}\right)$, in which $\sigma$ corresponds to the Von Mises stress and $\sigma_{u l t}$ is the average ultimate stress of the several sandwich beams tested.

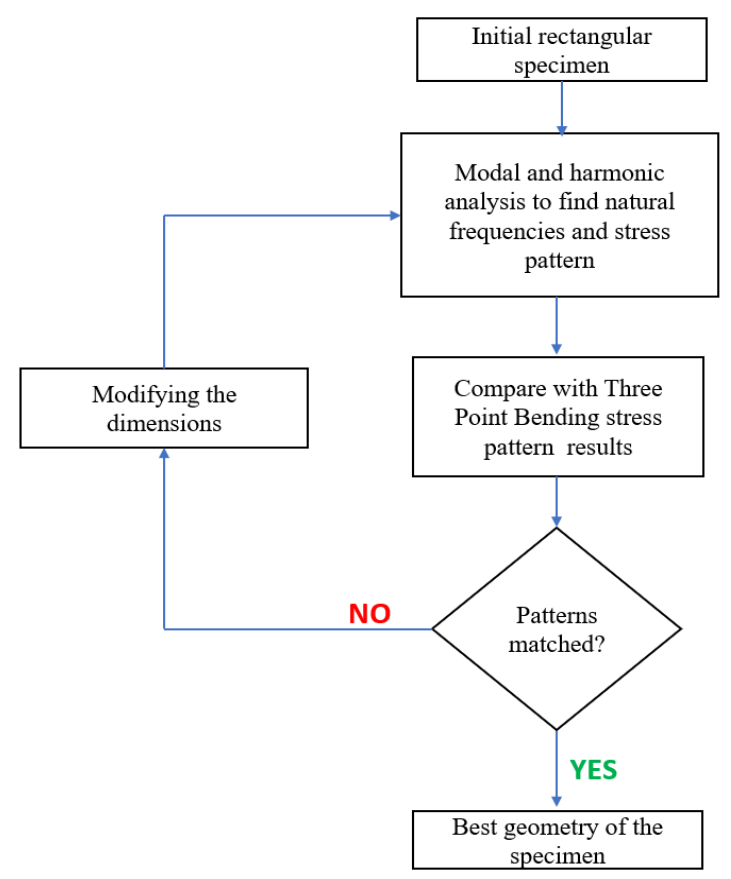

Figure 4. Approach used in the optimization design of the vibration specimen.

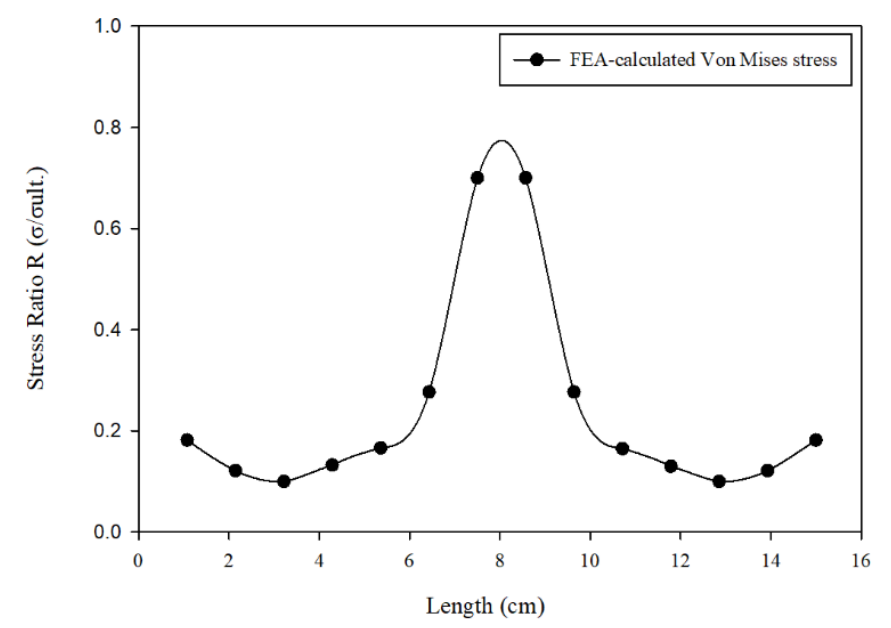

Figure 5. The centerline stress ratio profile that was used in the specimen design.

A beam with dimensions of $16 \mathrm{~cm} \times 3.81 \mathrm{~cm} \times 1.2 \mathrm{~cm}$ underwent fully reversible $(R=-1) 0.75 \mathrm{~Hz}$ sinusoidal loading in the three-point bending simulation (see stress profile in Figure 5). This profile was used as the baseline for designing the vibration test specimen.

Vibrations occurring at the first resonance frequency usually created mode shapes with the largest displacements. For a cantilever beam, this corresponded to a beam oscillating similar to its static (weight) deflection pattern, thus producing the highest stress level at the cantilevered end during its motion.

In order to establish the desired profile, similar to Figure 5, geometric changes needed to be performed. Only core thickness modifications were performed, since the initial analysis demonstrated that increasing the core thickness reduces the stress significantly more than increasing the face sheet thickness. The beam modeled in three-point bending was limited in dimensions due to the jig that was available. The vibration beam was 
designed so as to optimize the vibration's available experimental space. A rectangular beam with the length of $390 \mathrm{~mm}$ and the width of $38.1 \mathrm{~mm}$ was chosen. During the geometric modifications, the beam's length and width were held constant. The three-point bending face sheet layout (0-90 carbon face sheets bonded with Epoxy resin, $0.5 \mathrm{~mm}$ thick) was adopted and held constant in the design process. In addition, the available amplifier and electromagnet shaker restricted reasonable repeatable experiments to a first resonance of around $40 \mathrm{~Hz}$.

The design process of the specimen entailed iterative variations in the numerical values of the parametric variables chosen for the design. In general, this process is not limited to the number used in the research. The values can be increased or decreased. A schematic showing the relative location, with respect to the beam's span of the parametric variables used in the design of the core' geometry, is shown in Figure 6.

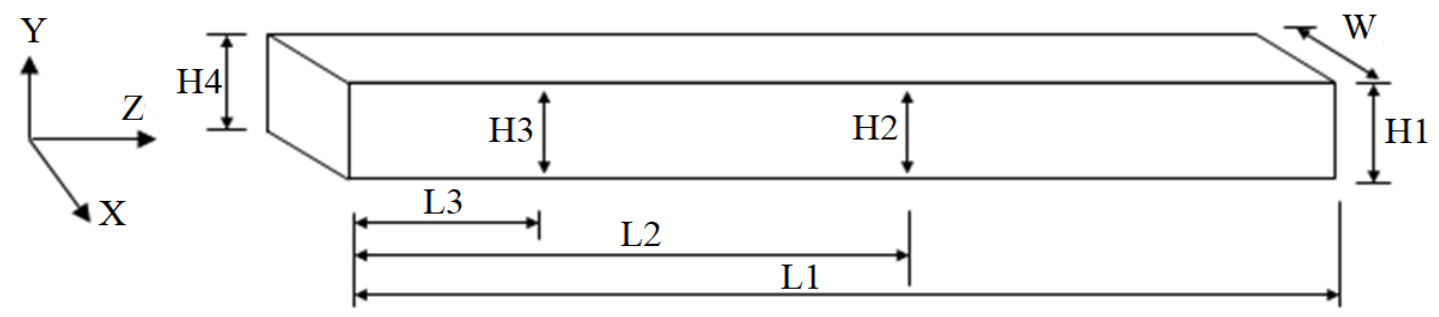

Figure 6. Parametric model used in the geometric optimization.

As mentioned before, the width (W) and the total length (L1) were held constant. The thickness at $\mathrm{H} 1, \mathrm{H} 2, \mathrm{H} 3$, and $\mathrm{H} 4$, corresponding to positions L1, L2, L3, and the origin 0, respectively, were varied.

In order to reduce the stress at the cantilevered end, $\mathrm{H} 4$ was increased. By decreasing the values of $\mathrm{H} 3$ and $\mathrm{H} 2$, the position of the maximum stress occurring on the beam's top face sheet changed. In the design process, changes were made in 10 percent increments. After each change, FEA modal analysis was performed to obtain the new stress pattern and ensure that resonance frequency did not surpass $40 \mathrm{~Hz}$. It should be noted that $\mathrm{H} 2$ and $\mathrm{H} 3$ could be varied singularly or simultaneously. This process was repeated until a desired pattern was achieved. Figure 7 shows the stress pattern that occurs during the first mode of vibration without any geometric variation (in the rectangular beam). Figure 8 shows the stress pattern trend after several iterations in which $\mathrm{H} 1$ and $\mathrm{H} 4$ were increased while $\mathrm{H} 2$ and $\mathrm{H} 3$ were decreased.

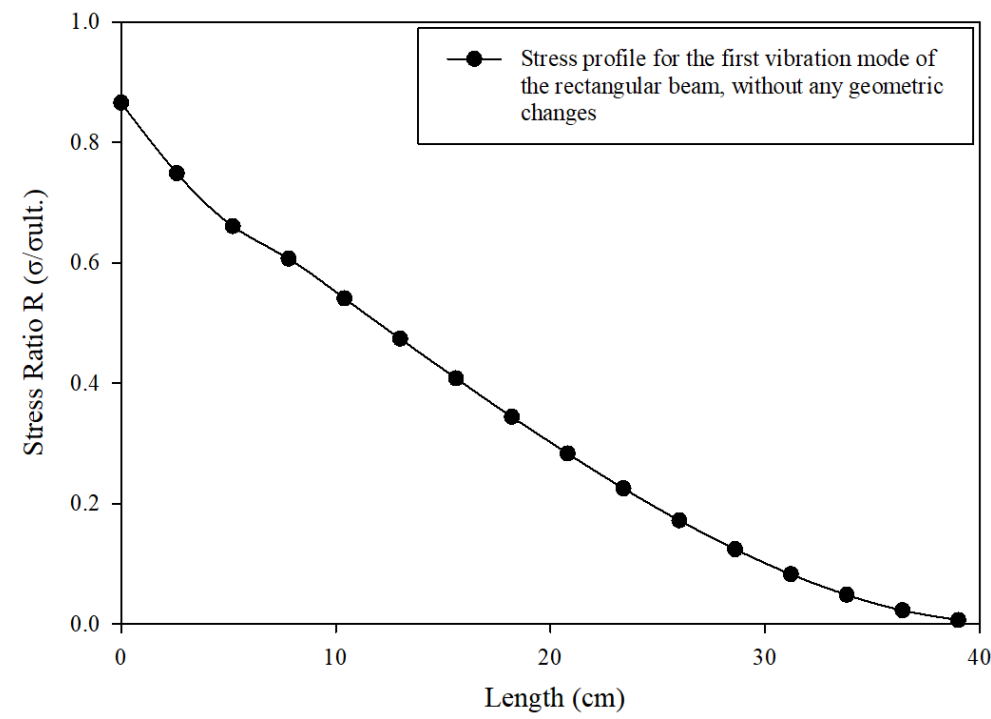

Figure 7. Stress profile in first mode without geometric changes. 


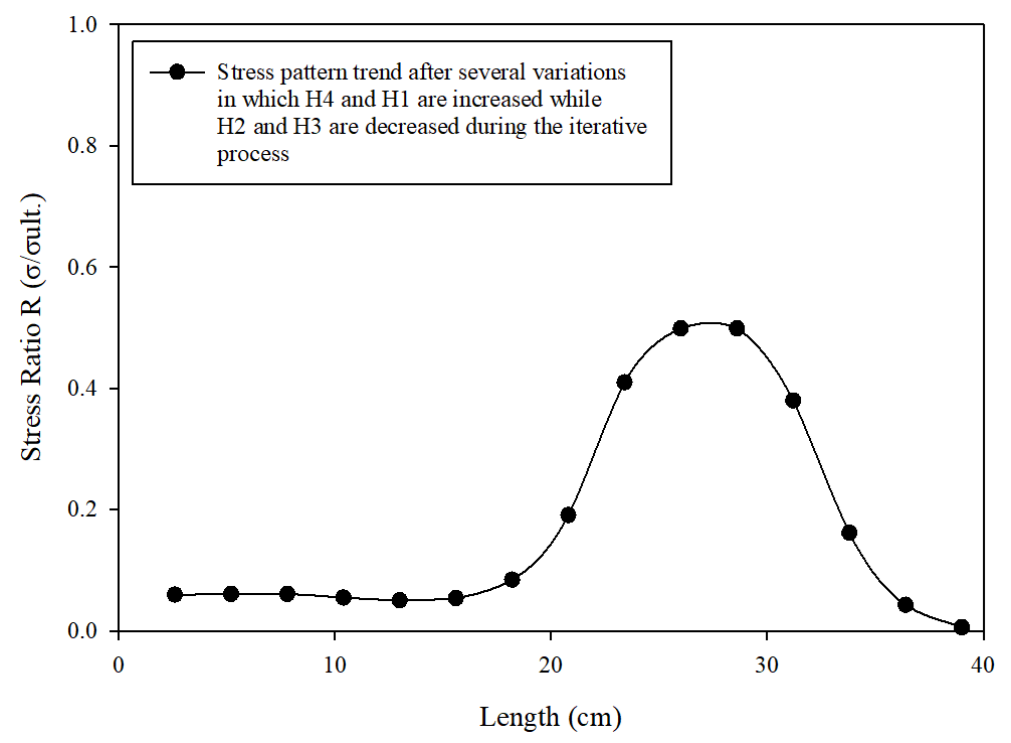

Figure 8. Stress profile pattern after several variations in the values of $\mathrm{H} 1-\mathrm{H} 4$ during the iterative process.

The stress ratio profile could be moved to the left by using a similar procedure in which L2 was decreased and L3 was increased. Figure 9 shows the trend in the stress pattern after several iterations.

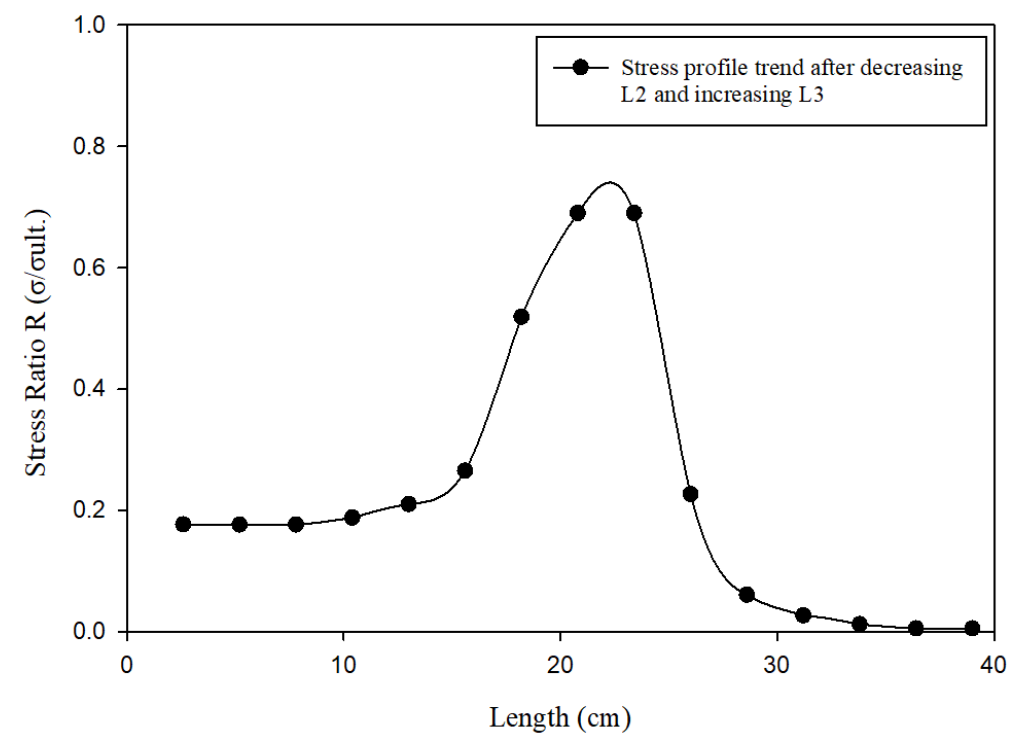

Figure 9. Stress profile after modifying L3 and L2.

The final Von Mises stress design profile, compared with that of the three-point bending profile, is shown in Figure 10.

It can be observed that the profile in Three-Point Bending was more acute than that of the optimized vibration specimen. The Three-Point Bending specimen had a smaller length, which produced a greater curvature. Despite the difference in profiles, the resultant specimen was valid. The greatest stress values occurred in the area that was designed to fatigue in vibration. A finer approximation in the profile could possibly be obtained by further modifications, such as reducing $\mathrm{H} 2$ and $\mathrm{H} 3$ even more; however, this may lead to a very thin region that might be impractical to manufacture. 


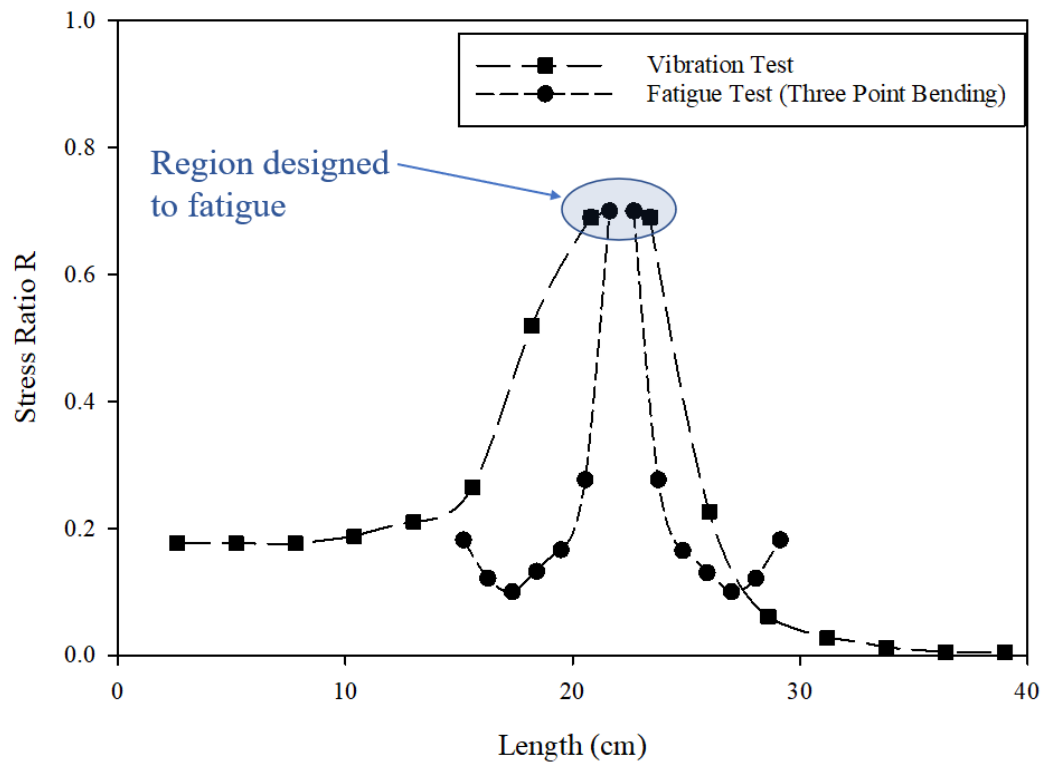

Figure 10. Comparison of the stress profiles obtained with Three-Point Bending and the final vibration test specimen (final Von Mises design profile).

\subsection{Experimental Set-Up}

Three-point bending static tests and fatigue lifetime tests on a rectangular beam (Figure 11) were performed using a servo hydraulic MTS-810 machine [41]. A 100-N/min loading rate was used for static testing, yielding an average ultimate stress of $289.38 \mathrm{MPa}$. A $0.75 \mathrm{~Hz}$ sinusoidal waveform at stress ratios $\left(R=\left(\sigma / \sigma_{u l t}\right)\right)$ of $0.77,0.70,0.62$, and 0.55 was used for fatigue testing. The contact stress was minimized by using damping rubbers around the loading pins. A total of twenty specimens were tested.

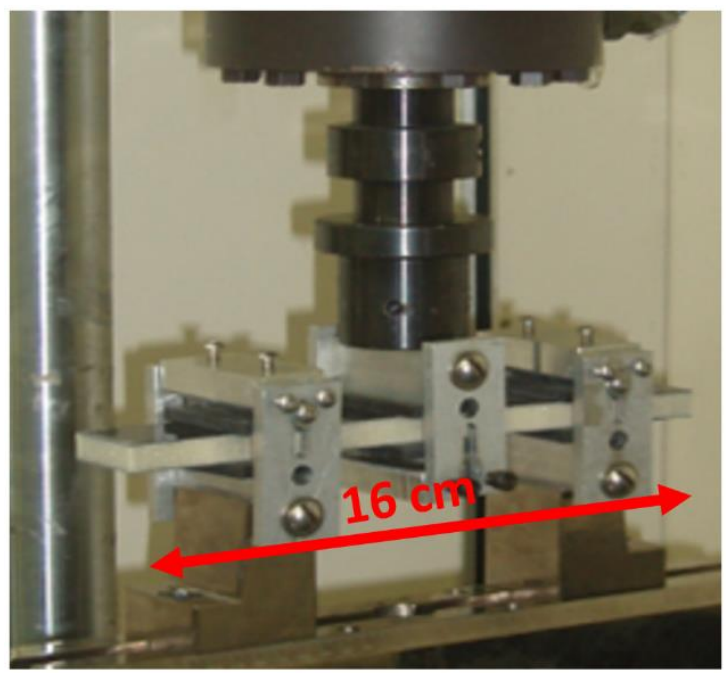

Figure 11. Material MTS 810 test system.

Before any vibration test specimens were designed, the temperature behavior of several beams was examined under resonance, yielding a maximum increase of no more than $2{ }^{\circ} \mathrm{C}$ for all cases examined. This $2{ }^{\circ} \mathrm{C}$ increase in temperature was considerably less than that found in other works using three-point bending [12]. This effect was most probably due to the fact that the beam's motion under resonance provided a forced convective cooling effect not found in three-point bending tests.

Vibration testing required the manufacturing of an optimal shape specimen. Specimen dimensions were exported to a computer numerical controlled (CNC) machine to manu- 
facture the foam core shape. VARTM manufacturing was used to attach the face sheets. A 20-day drying period was used to ensure proper curing of the Epoxy resin. Figure 12 shows the final double cantilevered specimen used for cantilever beam testing.

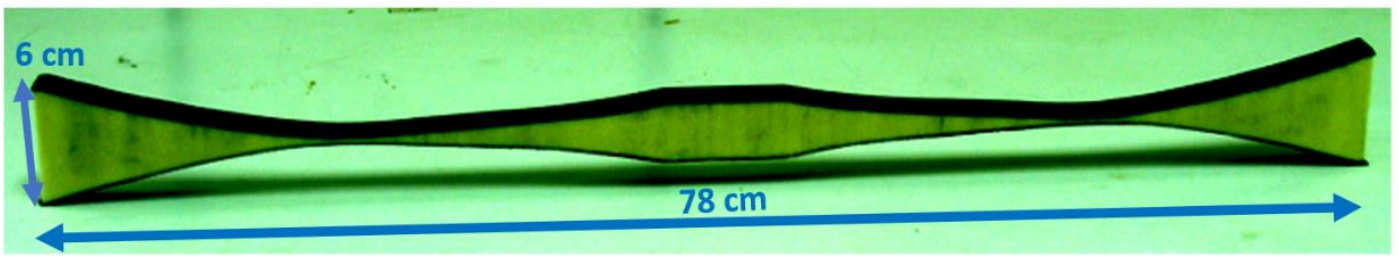

Figure 12. Final sandwich specimens design used in fatigue vibration (total length $78 \mathrm{~cm}$, end height $6 \mathrm{~cm})$.

Vibration testing was performed with an electrodynamic VTS-VG150 shaker, with a loading capacity of $667 \mathrm{~N}$ and a maximum operating frequency of $4000 \mathrm{~Hz}$. Shaker input signals were generated using a dynamic signal analyzer. The experimental setup is depicted in Figures 13 and 14. A verified FEA model, along with force transducer measurements, shaker amplifier input adjustments, and laser Doppler vibrometer measurements, ensured that the proper deflection was obtained, yielding the correct stress ratio at the desired area during testing. Beams were vibrated at their corresponding first resonance. As with three-point bending, five specimens were evaluated at each of the stress ratios used $(0.77$, $0.70,0.62$, and 0.55).

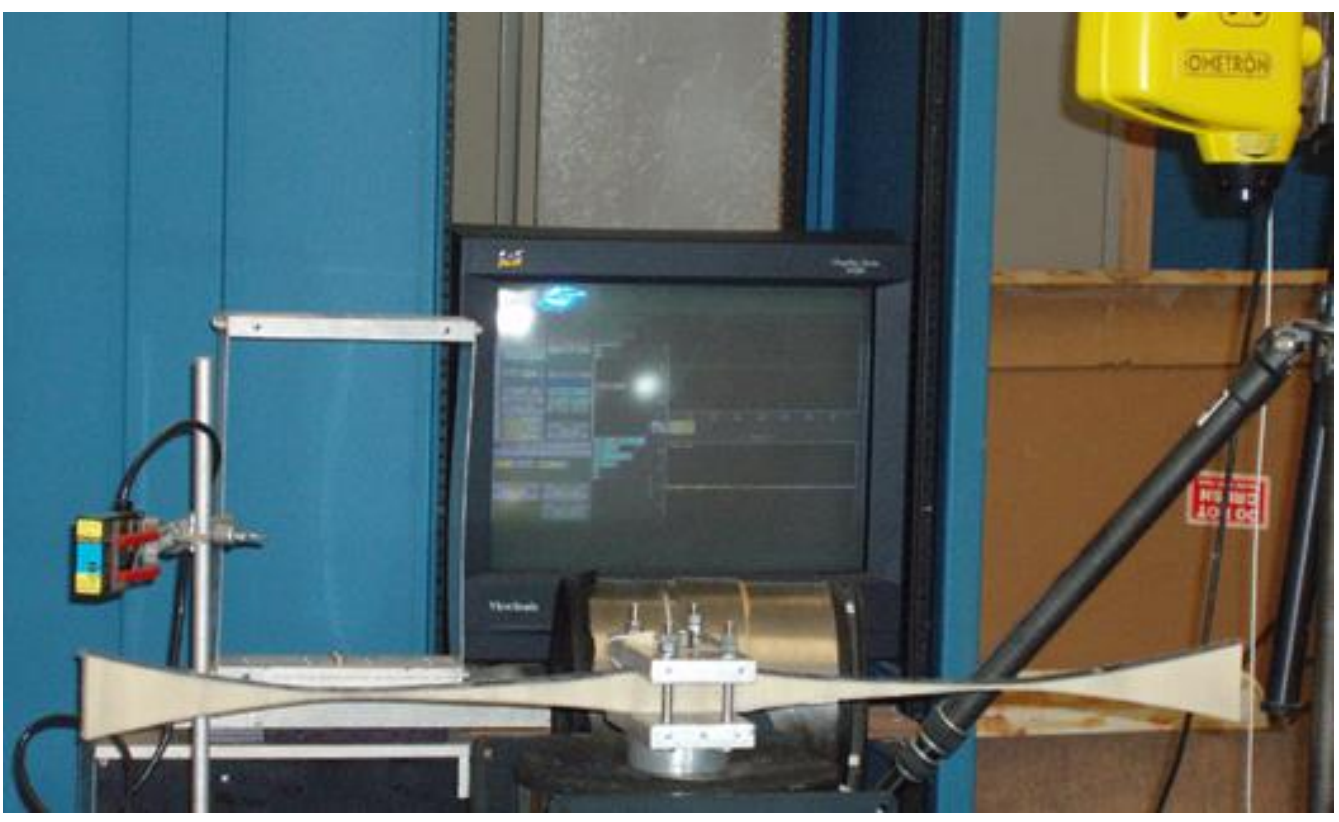

Figure 13. Experimental setup for composite specimen vibration using the double cantilever technique. 


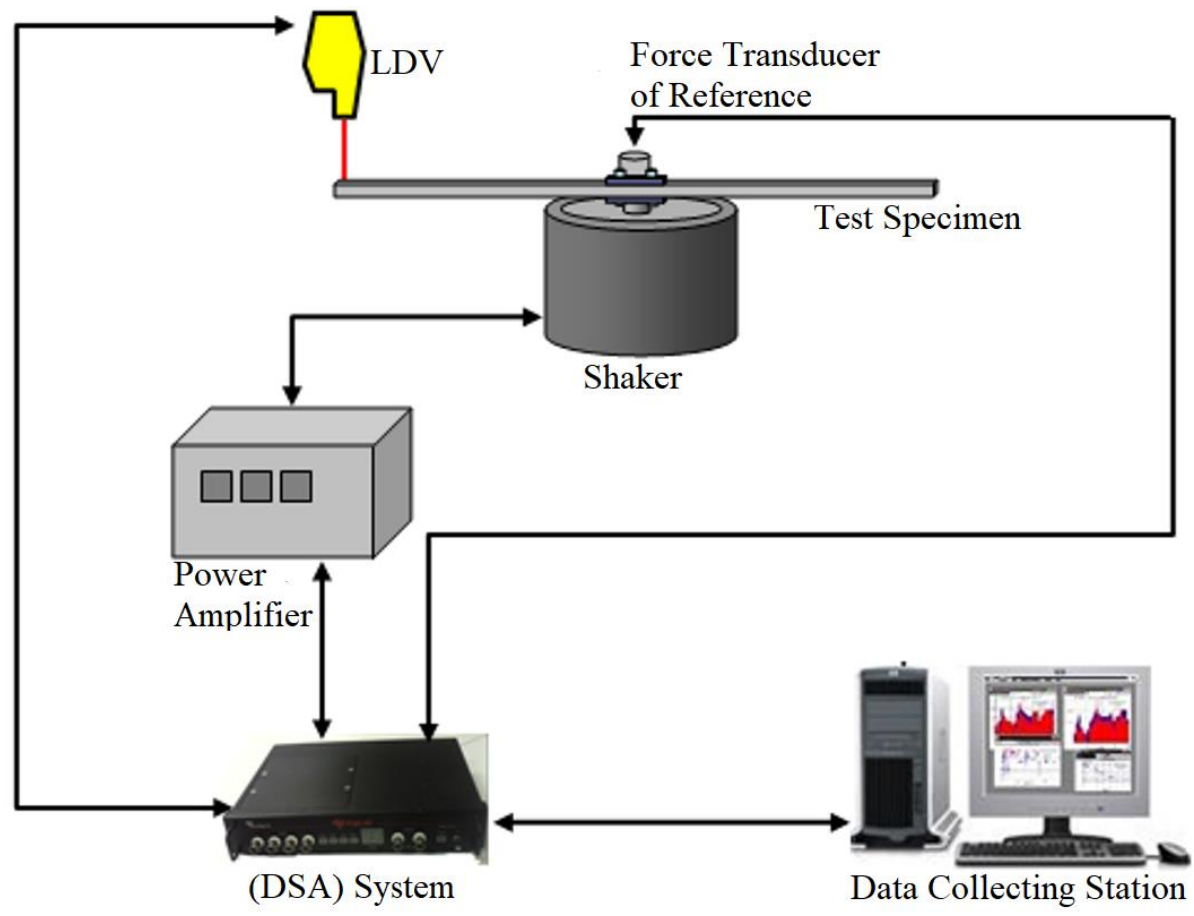

Figure 14. Schematic outline of the experimental vibration setup.

\section{Experimental Results}

This vibration technique does not have any type of contact on the beam (see Figures 13 and 14) as compared to other fatigue methods such as four- and three-point bending.

Vibration fatigue testing was performed at $32 \mathrm{~Hz}$. All beams failed abruptly in a core shear failure with a debonding of the material similar to that observed in threepoint bending tests, as shown in Figure 15. Due to the relatively high frequency and the catastrophic nature of the failure, shear crack growth could not be observed.

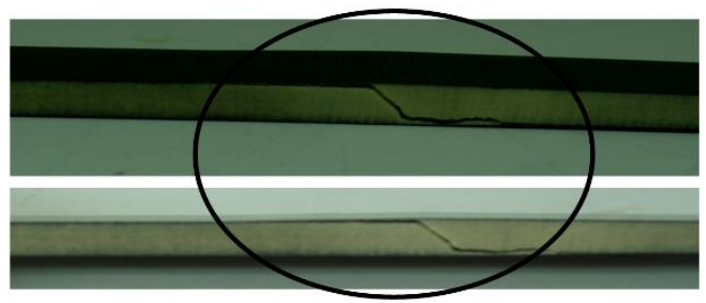

(a)

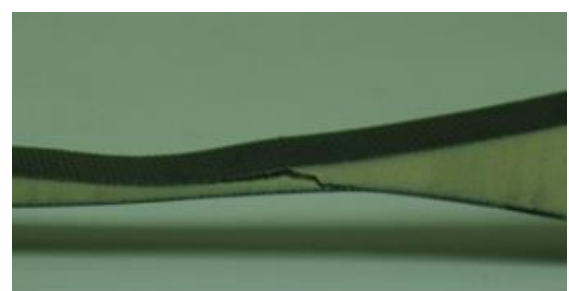

(b)

Figure 15. (a) Failure found in three-point bending tests; (b) failure found in vibration tests.

The FEA vibration resonance frequency predictions, along with the average number of cycles to failure under vibration and three-point bending with their respective stress ratios, are shown in Table 2.

In both three-point bending and vibration testing, specimens were repeatedly cycled at a given stress ratio until failure. The S-N curve that defines the number of cycles to failure is shown in Figure 16. 
Table 2. Experimental results from Vibration and Three-Point Bending tests.

\begin{tabular}{ccccc}
\hline Stress Ratio & $\begin{array}{c}\text { Experimental } \\
\text { Result (Hz) }\end{array}$ & $\begin{array}{c}\text { Predicted } \\
\text { Frequency (Hz) }\end{array}$ & $\begin{array}{c}\text { Average Number of Cycles } \\
\text { to Failure (Vibrations) }\end{array}$ & $\begin{array}{c}\text { Average Number of Cycles to } \\
\text { Failure (Three-Point Bending) }\end{array}$ \\
\hline 0.77 & 32.5 & 31 & 5954 & 4507 \\
\hline 0.70 & 31.95 & 31 & 18,078 & 14,726 \\
\hline 0.62 & 32.25 & 31 & 85,461 & 66,741 \\
\hline 0.55 & 32.5 & 31 & 186,876 & 166,742 \\
\hline
\end{tabular}

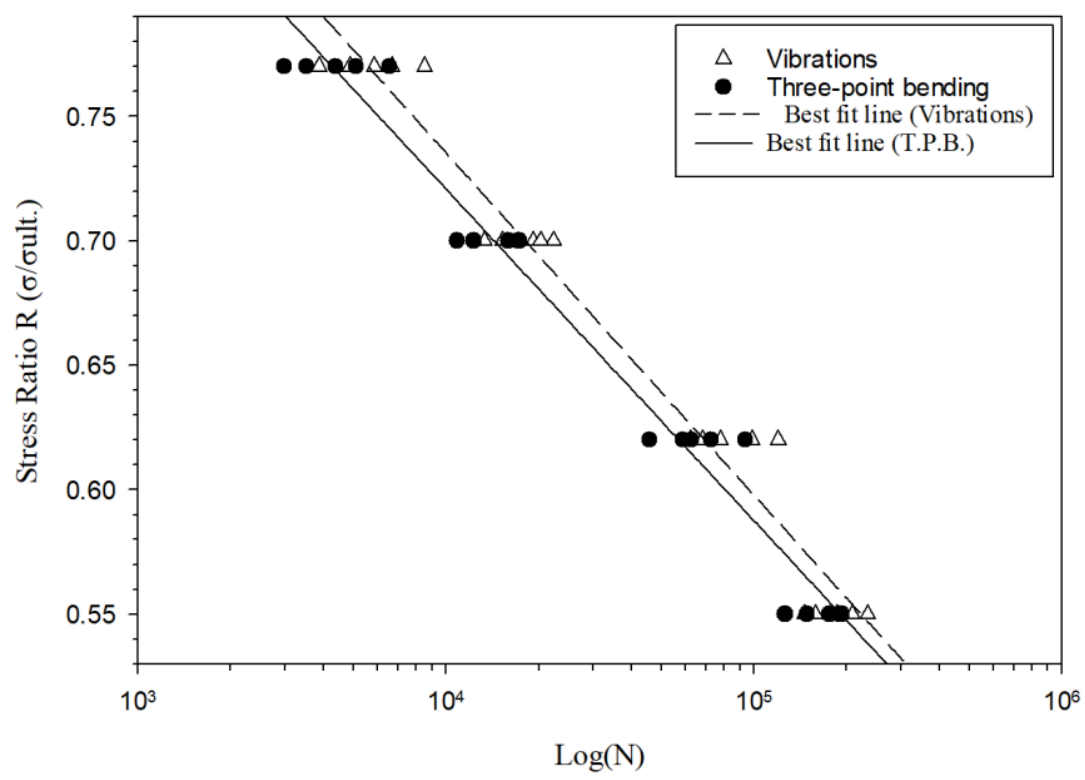

Figure 16. Comparison of sandwich composite fatigue life curves. Failures obtained during threepoint bending test and vibration test.

The vibration fatigue and three-point bending S-N regression lines shown in Figure 16 are almost parallel, suggesting that the two techniques yield consistent results with the same material configuration. The observed linear behavior and data scatter in three-point bending and vibration testing is in agreement with previous results, as reported in the literature $[1,2,12,42]$.

The total face sheet thickness to core ratio in the three-point bending specimen was $\left(t_{f} / t_{c}=0.08\right)$. In the original S-N curve generated, the effect of contact stress was not considered in the three-point bending stress ratio calculation. It is clearly evident that the fatigue life predicted with vibration testing yields a longer life than that predicted by three-point bending at the same stress level. One possible explanation for this behavior can be attributed to the jig-beam contact (see Figure 11) used to hold the three-point bending specimens. The vibration testing does not contain any contact points (see Figure 13). The Von Mises centerline stresses were calculated with a typical three-point bending test formulation that does not consider the effects of contact stress [43]. By considering contact stress $[44,45]$, representative values of the Von Mises centerline stresses occurring in threepoint bending can be estimated using Equation (2) [45].

$$
P_{0}=\left(\frac{P^{\prime} E^{*}}{\pi R}\right)^{1 / 2}
$$


where $P_{0}$ is the stress caused by the maximum pressure over the specimen. $P^{\prime}$ is the applied force per unit length. $R$ is the effective curvature of the loading pin including the damping rubbers, and $E^{*}$ is the contact modulus and is determined from Equation (3) [45].

$$
\frac{1}{E^{*}}=\frac{1-v_{1}^{2}}{E_{1}}+\frac{1-v_{2}^{2}}{E_{2}}
$$

In Equation (3), the modulus of elasticity and Poisson ratio for the damping rubber and foam are given by $E_{1}, v_{1}, E_{2}$, and $v_{2}$, respectively.

As a result of this consideration, the Von Mises stresses at the surface centerline were recalculated with a compression stress due to the contact effect and tension as a result of the bending moment. Table 3 shows the results of the predicted cycles to failure using the vibration regression equation best fit line, and those actually obtained from three-point bending (TPB).

Table 3. Experimental results from Three-Point Bending and Vibration tests, considering the contact stress.

\begin{tabular}{cccc}
\hline Corrected Contact Stress Ratio & \multicolumn{1}{c}{$\begin{array}{c}\text { Average Cycles to Failure } \\
\text { Using Three-Point Bending }\end{array}$} & $\begin{array}{c}\text { Predicted Cycles to Failure } \\
\text { Using Vibrations }\end{array}$ & $\begin{array}{c}\text { Error Difference } \\
\text { (Using TPB as Base) }\end{array}$ \\
\hline 0.78 & 4507 & 4742 & $5.22 \%$ \\
\hline 0.71 & 14,726 & 15,332 & $4.12 \%$ \\
\hline 0.63 & 66,741 & 58,586 & $12.22 \%$ \\
\hline 0.56 & 166,742 & 189,365 & $13.56 \%$ \\
\hline
\end{tabular}

By correcting the effect of contract stress in the calculation of the stress ratios determined in three-point bending, a compatible fatigue prediction technique can be seen. In the original S-N curve generated, the effect of contact stress was not considered in the three-point bending stress ratio calculation. The separation of the two best fit lines for vibrations and three-point bending, shown in Figure 16, was reduced by including the effect of contact stress in the three-point bending stress ratios. The new S-N three-point bending curve, along with the vibration S-N curve showing this improvement, is given in Figure 17.

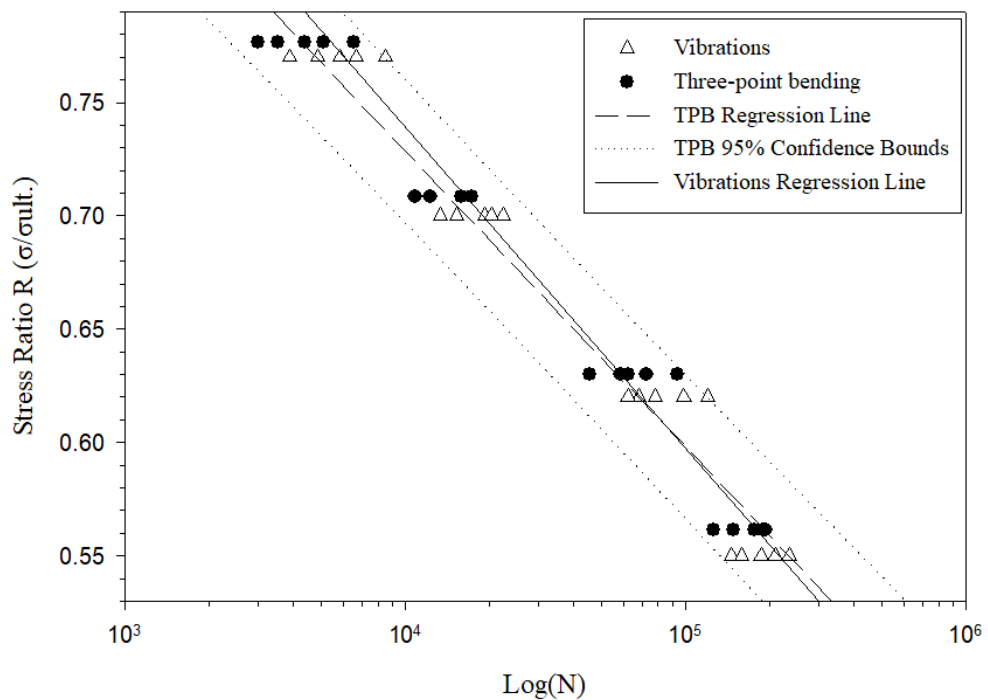

Figure 17. Fatigue lifetime S-N curves for Vibrations and Three-Point Bending. The TPB stress ratio calculation takes into account the effect of contact stress. 


\section{Discussion}

The results of this method are very promising in terms of time revenue savings. Significant time revenue savings were observed during vibration testing. Test specimens were vibrated 42 times faster than those performed with three-point bending testing. Vibration samples were vibrated at $32 \mathrm{~Hz}$, whereas three-point bending specimens were tested at $0.75 \mathrm{~Hz}$.

To better understand this effect, consider the hypothetical case of testing a material that yields at least 100,000 cycles per data point with equipment having a range of $1-5 \mathrm{~Hz}$.

As seen in Table 4, the time for obtaining a data point at a frequency of $5 \mathrm{~Hz}$ will require at least $5.55 \mathrm{~h}$.

Table 4. Costs associated with testing at different frequencies.

\begin{tabular}{cccc}
\hline Frequency, Hz & Time per Data Point & $\begin{array}{c}\text { Time Required for } \\
\text { Obtaining 10 Data Points }\end{array}$ & $\begin{array}{c}\text { Time Required for Curve } \\
\text { Four different Stress Ratios } \\
\text { (10 Data Points/Stress Ratio) }\end{array}$ \\
\hline 5 & $5.5 \mathrm{~h}$ & 2.29 days & 9.16 days \\
\hline 32 & $52 \mathrm{~min}$ & $8.67 \mathrm{~h}$ & 1.45 days \\
\hline
\end{tabular}

In contrast, testing at $32 \mathrm{~Hz}$, a frequency not attainable in many conventional legacy systems, would allow a time revenue saving of $84.3 \%$. In cases where various data points are required at each stress ratio, the time needed for geometry design and preparation is justified. However, the proposed methodology is not recommended for just one or two tests. In addition, the temperature increase in the specimens was measured to be less than $2{ }^{\circ} \mathrm{C}$. This increase was shown to be negligible as compared to the results observed in a previous study that investigated the effects of temperature and frequency from 3 to $15 \mathrm{~Hz}$ using a three-point bending configuration, which produced errors of up to $100 \%$ for fatigue life [12]. This lack of a temperature increase was most likely due to the convective heat transfer present in the periodic motion of the beam moving through air during vibrations. The results from vibration testing were shown to be reliable, producing a similar S-N curve as given by three-point bending results. When considering the effects of contact stress, all vibration results fell within the $95 \%$ confidence intervals of the three-point bending data for all ratios tested.

\section{Conclusions}

A vibration technique was demonstrated to be an alternative means of obtaining threepoint-bending-compatible lifetime data. It is clearly evident that the proposed vibration method yields results that fall within the three-point bending $95 \%$ confidence level, showing a good correlation to justify its use. The proposed method is significantly faster than the conventional three-point bending test performed with a hydraulic servo machine. This methodology has the potential to offer significant time revenue savings, especially when various repetitive tests at specific stress ratios are required to generate $\mathrm{S}-\mathrm{N}$ curves with statistical information, overcoming the time needed in the geometry design.

Author Contributions: Conceptualization, F.A.J.-A., D.S.A., B.S. and M.M.; methodology, F.A.J.-A., D.S.A., B.S. and M.M.; software, F.A.J.-A., D.S.A., B.S. and M.M.; validation, F.A.J.-A., D.S.A., B.S. and M.M.; formal analysis, F.A.J.-A., D.S.A., B.S. and M.M.; investigation, F.A.J.-A., D.S.A., B.S. and M.M.; resources, F.A.J.-A., D.S.A., B.S. and M.M.; data curation, F.A.J.-A., D.S.A., B.S., M.M., A.C., U.K.V. and J.M.V.B.; writing—original draft preparation, F.A.J.-A., M.M., D.S.A., B.S. and A.C.; writing-review and editing, M.M., F.A.J.-A., A.C., U.K.V., J.M.V.B., B.S. and D.S.A.; visualization, M.M., F.A.J.-A., A.C., D.S.A., B.S., J.M.V.B. and U.K.V.; supervision, F.A.J.-A., D.S.A., B.S. and M.M.; project administration, F.A.J.-A., D.S.A., B.S. and M.M.; funding acquisition, F.A.J.-A., D.S.A., B.S., U.K.V. and M.M. All authors have read and agreed to the published version of the manuscript. 
Funding: This research was funded by the Puerto Rico Science, Technology and Research Trust (PRSTRT), grant agreement number 2020-00135, and the Office of Naval Research (ONR), grant number N00014-06-1-1043.

Institutional Review Board Statement: Not applicable.

Informed Consent Statement: Not applicable.

Data Availability Statement: Not applicable.

Conflicts of Interest: The authors declare no conflict of interest. The funders had no role in the design of the study; in the collection, analyses, or interpretation of data; in the writing of the manuscript, or in the decision to publish the results.

\section{References}

1. Zenkert, D.; Shipsha, A.; Burman, M. Fatigue of closed cell foams. J. Sandw. Struct. 2006, 8, 517-538. [CrossRef]

2. Sharma, S.; Gibson, R.; Ayorinde, E. Fatigue of Foam and Honeycomb Core Composite Sandwich Structures: A Tutorial. J. Sandw. Struct. 2006, 8, 263-319. [CrossRef]

3. Stone, H. Fatigue Testing of Flexible Foams. J. Cell. Plast. 1983, 19, 47-60. [CrossRef]

4. Roosen, D. Fatigue behavior of sandwich foam core materials: Comparison of different core materials. J. Adv. Mater.-Covina 2005, 37, 38-42.

5. Yau, S.; Mayer, G. Fatigue crack propagation in polycarbonate foam. Mater. Sci. Eng. 1986, 78, 111-114. [CrossRef]

6. Noble, F.; Lilley, J. Fatigue crack growth in polyurethane foam. J. Mater. Sci. 1981, 16, 1801-1808. [CrossRef]

7. Mahi, A.; Farooq, M.; Sahraoui, D. Mechanical behavior of Sandwich Composite Material under Cyclic Fatigue. In Proceedings of the New Trends in Fracture and Fatigue Conference, Metz, France, 8-9 April 2002.

8. Kulkarni, N.; Mahfuz, H.; Jeelani, S.; Carlsson, L. Fatigue Crack Growth and Life Prediction of Foam Core Sandwich Composite under Flexural Loading. Compos. Struct. 2003, 59, 499-505. [CrossRef]

9. Caprino, G. Predicting Fatigue Life of Composite Laminates Subjected to Tension-Tension Fatigue. J. Compos. Mater. 2000, 34, 1334-1355. [CrossRef]

10. Clark, S.D.; Shenoi, R.A.; Allen, H.G. Modeling the Fatigue Behavior of Sandwich Beams under Monotonic, 2-step and Block Loading Regimes. Compos. Sci. Technol. 1999, 59, 471-486. [CrossRef]

11. Berkowitz, C.K.; Johnson, W.S. Fracture and Fatigue Tests and Analysis of Composite Sandwich Structure. J. Compos. Mater. 2005, 39, 1417-1431. [CrossRef]

12. Kanny, K.; Mahfuz, H.; Thomas, T.; Jeelani, S. Temperature Effects on the Fatigue Behavior of Foam Core Sandwich Structures, Polymers and Polymer Composites. Polym. Polym. Compos. 2004, 12, 551-559.

13. Wu, W.F.; Lee, L.J.; Choy, S.T. A Study of Fatigue Damage and Fatigue Life of Composite Laminates. J. Compos. Mater. 1996, 30, 123-137. [CrossRef]

14. Epaarachchi, J.A.; Clausen, P.D. A New Cumulative Fatigue Damage Model for Fiber Reinforced Plastic Composites under Step/Discrete Loading. Compos. Part A Appl. Sci. Manuf. 2005, 36, 1236-1245. [CrossRef]

15. Collins, J.A. Failure of Materials in Mechanical Analysis, Prediction, Prevention, 2nd ed.; Wiley-Interscience: Hoboken, NJ, USA, 1993.

16. Piersol, A.G.; Paez, T.L. Harris' Shock and Vibration Handbook, 6th ed.; McGraw-Hill: New York, NY, USA, 1988.

17. Instron. Available online: https:/ / www.instron.com/ (accessed on 16 October 2021).

18. Zwick Roell. Available online: https:/ / www.Zwickroell.com (accessed on 16 October 2021).

19. Kanny, K.; Mahfuz, H. Flexural fatigue characteristics of sandwich structures at different loading frequencies. Compos. Struct. 2005, 67, 403-410. [CrossRef]

20. Sun, C.; Chan, W. Frequency effect on the fatigue life of a laminated composite. ASTM Spec. Tech. Publ. 1979, 674, 418-430.

21. Barron, V.; Buggy, M.; McKenna, N. Frequency effects on the behavior of Carbon fiber reinforced polymer laminates. J. Mater. Sci. 2001, 36, 1755-1761. [CrossRef]

22. Zou, Y.; Tong, L.; Steven, P. Vibration based model dependent damage (delamination) identification on health monitoring for composite structures: A review. J. Sound Vib. 2000, 230, 357-378. [CrossRef]

23. Ayorinde, E.O. Elastic constants of thick orthotropic composite plates. J. Compos. Mater. 1995, 29, 1025-1039. [CrossRef]

24. Reifsnider, K.; Stinchcomb, W.; O'Brien, T. Frequency effects on a stiffness based failure criterion in flawed composite specimens. ASTM Spec. Tech. Publ. 1977, 636, 171-184.

25. Gibson, R.F. Modal Vibration Response Measurements for Characterization of Composite Materials and Structures. Compos. Sci. Technol. 2000, 60, 2769-2780. [CrossRef]

26. Liew, K.M.; Xiang, Y.; Kitiponchai, S. Research on Thick Plate Vibration: A Literature Survey. J. Sound Vib. 1995, 180, 163-176. [CrossRef]

27. Penn, L.; Jump, J.; Greenfield, M. Use of the free vibration spectrum to detect delamination in thick composites. J. Compos. Mater. 1999, 33, 54-72. [CrossRef]

28. Mead, D.; Markus, S. The forced vibration of a three-layer, damped sandwich beam with arbitrary boundary conditions. J. Sound Vib. 1969, 10, 163-175. [CrossRef] 
29. Kosmatka, J.; Ricles, J. Damage detection in structures by modal vibration characterization. J. Struct. Eng. 1999, 125, 1384-1392. [CrossRef]

30. Salawu, O.S. Detection of structural damage through changes in frequency: A review. Eng. Struct. 1997, 19, 718-723. [CrossRef]

31. Shu, D. Vibration of sandwich beams with double delaminations. Compos. Sci. Technol. 1995, 54, 101-109. [CrossRef]

32. Peeters, B.; Maeck, J.; Roeck, G. Vibration-based damage detection in civil engineering: Excitation sources and temperature effects. Smart Mater. Struct. 2001, 10, 518-527. [CrossRef]

33. American Society of Testing and Materials. Annual Book of ASTM Standards, 2007 ed.; ASTM International: West Conshohocken, PA, USA, 2007.

34. Scott-Emuakpor, O.; Shen, M.H.H.; George, T.; Cross, C.J.; Calcaterra, J. Development of an improved high cycle fatigue criterion. J. Eng. Gas Turbines Power 2007, 129, 162-169. [CrossRef]

35. George, T.; Seidt, J.; Shen, M.H.H.; Nicholas, T.; Cross, C. Development of a novel vibration-based fatigue testing methodology. Int. J. Fatigue 2004, 26, 477-486. [CrossRef]

36. George, T.; Shen, M.H.H.; Scott-Emuakpor, O.; Nicholas, T.; Cross, C.; Calcaterra, J. Goodman diagram via vibration-based fatigue testing. J. Eng. Mater. Technol. 2005, 127, 58-64. [CrossRef]

37. Peralta-Serrano, A. Innovative Vibration Technique as a Viable Substitute for Conventional Three Point Bending Fatigue Testing. Master's Thesis, University of Puerto Rico at Mayaguez, Mayaguez, PR, USA, 2008.

38. FR-7106 polyurethane foam, General Plastics Manufacturing Company. Available online: https://www.generalplastics.com/wpcontent/uploads/2018/09/FR-7100-TDS.pdf (accessed on 7 August 2021).

39. Just-Agosto, F.; Shafiq, B.; Serrano, D. Development of a Damage Detection Scheme Applicable to Sandwich Composites. J. Sandw. Struct. 2007, 9, 343-363. [CrossRef]

40. Vanderplaats, G.N. Numerical Optimization Techniques for Engineering Design, 3rd ed.; McGraw-Hill: Colorado Springs, CO, USA, 2001.

41. Model 810 Datasheet-MTS Systems Corporation-Material Testing System I Engineering360 (globspec.com). Available online: https:/ / datasheets.globalspec.com/ds/2488/MTSSystems/CA6486D7-C041-412E-9B6C-757F618E3956 (accessed on 15 December 2021).

42. Peralta, A.; Just-Agosto, F.; Shafiq, B.; Serrano, D. Innovative vibration technique applied to polyurethane foam as a viable substitute for conventional fatigue testing. J. Mech. Behav. Mater. 2012, 21, 61-68. [CrossRef]

43. American Society of Testing and Materials. ASTM D790-07e1, Standard Test Methods for Flexural Properties of Unreinforced and Reinforced Plastics and Electrical Insulating Materials; ASTM International: West Conshohocken, PA, USA, 2007.

44. Collins, J.A. Mechanical Design of Machine Elements and Machines: A Failure Prevention Perspective; John Wiley \& Sons, Inc.: Hoboken, NJ, USA, 2002.

45. Bull, S.J. Elastic Contact Stress Formulae. Available online: http://www.staff.ncl.ac.uk/s.j.bull/ecstr.html (accessed on 7 August 2021). 